\title{
Soluble HLA-G, its diagnostic and prognostic value and potential target molecule for future therapy in cancer
}

\author{
Kluckova K, Durmanova V, Bucova M \\ Institute of Immunology, Faculty of Medicine, Comenius University, Bratislava, Slovakia. \\ maria.bucova@fmed.uniba.sk
}

\begin{abstract}
Human leukocyte antigen G (HLA-G) is a non-classical MHC class I molecule that regulates many immune functions. The physiologic HLA-G expression is restricted to foetal tissues such as: amniotic cells, erythroid precursors, and cytotrophoblasts, and, in adults, to immune-privileged organs. The ectopic expression in tumours could point out to a strategy used by malignant cells to escape the immune surveillance. There are two forms of HLA-G, membrane-bound and soluble. The structure of the soluble and membrane bound isoforms differs at the $\mathrm{C}$-terminus. The extracellular domain and the intracytoplasmic tail are replaced in the secreted isoforms by a short hydrophilic tail. These differences could serve as a marker to distinguish shed or proteolytically cleaved HLA-G isoforms from secreted HLA-G isoforms. HLA-G induces tolerance by inhibiting different cells and this function is mediated by binding of both soluble and membrane-bound HLA-G to the inhibitory receptors. There exists a consistent evidence in literature that HLA-G represents an important factor in determining prognosis in various types of cancer. In this review, we will focus on soluble form of HLA-G (sHLA-G) in cancers and its association with the prognosis of cancer patients, because this immune checkpoint molecule appears as a promising relevant target for cancer immunotherapy (Fig. 2, Ref. 115). Text in PDF www.elis.sk

KEY WORDS: cancer, diagnosis, HLA-G, soluble HLA-G, tumour.
\end{abstract}

\section{Introduction}

Human leukocyte antigen G (HLA-G) is a non-classical MHC class I molecule and immune function regulator. It was first observed/studied in the placenta, where it participates in the maternal tolerance toward the foetus (McMaster et al, 1995). The expression of HLA-G was also later discovered/observed in embryonic tissues, adult immune privileged organs, and cells of the hematopoietic lineage (Carosella et al, 2008). Ectopic HLA-G expression can be stimulated in varying types of cancer, such as melanoma (Bezuhly et al, 2008, Degenhardt et al, 2010, Ghandri et al, 2011, Paul et al, 1999, Paul et al, 1998, Wagner et al, 2000), head and neck (Dardano et al, 2012, Ghandri et al, 2011, Nunes et al, 2013), brain (Fan et al, 2016, Kren et al, 2010, Kren et al, 2011, Wastowski et al, 2013, Wiendl et al, 2002, Wischhusen et al, 2007), lung (Montilla et al, 2016, Urosevic et al, 2001, Wisniewski et al, 2015, Yan et al, 2015, Yie et al, 2007, Yie et al, 2007, Zhang et al, 2016), urogenital (Bijen et al, 2010, Gimenes et al, 2014, Hanak et al, 2009, Ibrahim et al, 2001, Langat et al, 2006, Li et al, 2012, Lin et al, 2013, Rodriguez et al, 2012, Rutten et al, 2014, Tronik-LeRoux et al, 2017, Zhang et al, 2016, Zheng et al, 2011),

Institute of Immunology, Faculty of Medicine, Comenius University, Bratislava, Slovakia

Address for correspondence: M. Bucova, MD, Institute of Immunology, Faculty of Medicine, Comenius University, Odborarske namestie 14, SK81372 Bratislava, Slovakia. gastrointestinal (Cao et al, 2011, Guo et al, 2015, Lin et al, 2011, Reimers et al, 2014, Swets et al, 2016, Zhu et al, 2010, Zeestraten et al, 2014), and breast cancers (daSilva et al, 2013, de Kruijf et al, 2010, Ferguson et al, 2012, He et al, 2010, Jeong et al, 2014, Kleinberg et al, 2006, Palmisano et al, 2002, Rolfsen et al, 2014, Singer et al, 2003), leukemias (Almeida et al, 2018, Nuckel et al, 2005, Xu et al, 2018), and lymphomas (Bielska et al, 2015, Diepstra et al, 2008, Urosevic et al, 2002). The expression of HLA-G in tumour lesions was first observed in melanoma (Wagner et al, 2000 ) and has been correlated with poor clinical outcomes (Amiot et al, 2011, de Kruijf et al, 2010, Guo et al, 2015, Nuckel et al, 2005, Yan et al, 2008). The ectopic expression in tumours could detail a strategy used by malignant cells to escape the immune detection (Curigliano et al, 2013).

This review will focus on the soluble form of HLA-G (sHLA-G) in cancers and its association with the prognosis of cancer patients, because this immune check-point molecule appears to be a promising target for cancer immunotherapy (Carosella et al, 2015).

\section{Origin, structure, and functions of HLA-G}

Like other HLA genes, HLA-G is located on chromosome 6p21.3. Within the non-classical HLA group, this gene remains the most polymorphic among the otherwise nearly non-polymorphic genes. To date, 69 alleles, 19 proteins, and 3 null alleles have been identified (IMGT/HLA release 3.39.0, January 2020, Carosella et al, 2015, Castelli et al, 2014, Robinson et al, 2015). HLA-G con- 
609-617

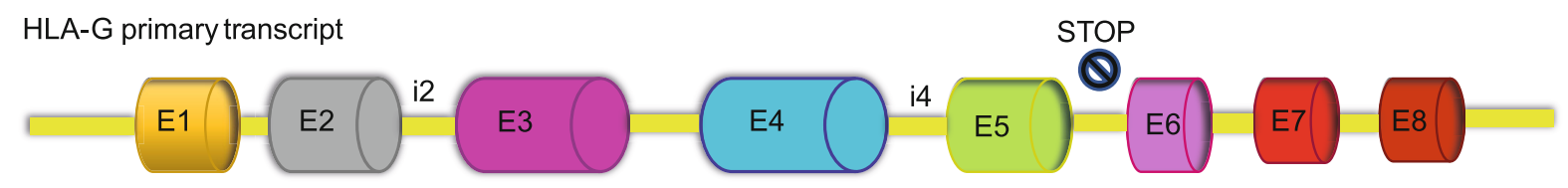

HLA-G isoforms

Membrane bound

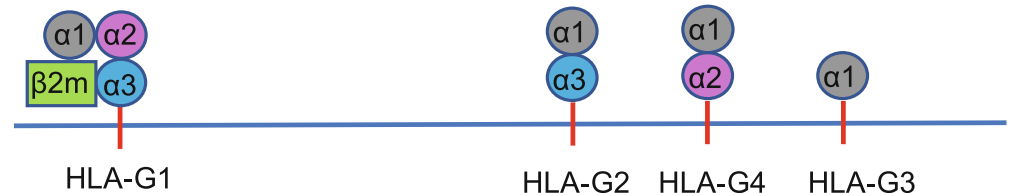

Soluble
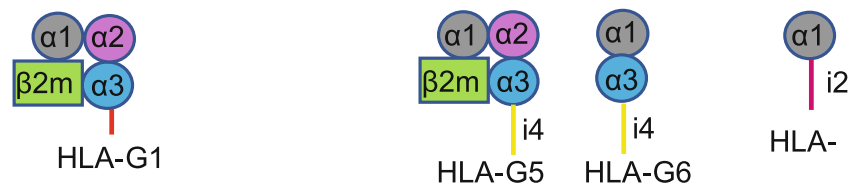

Fig. 1. Seven identified HLA-G isoforms generated by alternative splicing of HLA-G mRNA. Four membrane-bound (HLA-G1, -G2, -G3, -G4) and three soluble (HLA-G5, -G6, -G7) molecules. The extracellular structures of HLA-G1 and HLA-G5 contain $\alpha 1, \alpha 2$, and $\alpha 3$ domains; HLAG2 and HLA-G6 contain $\alpha 1$ and $\alpha 3$ domains; HLA-G3 contains $\alpha 1$ domains; HLA-G4 contains $\alpha 1$ and $\alpha 2$ domains; HLA-G7 contains an $\alpha 1$ domain linked to two amino acids encoded by intron 2.

sists of 8 exons; in all databases, exon 8 remains untranslated due to the presence of a stop code in exon 7 . The non-translated region of exon 8 is termed " 3 'untranslated region (3'UTR)" (Donadi et al, 2011). Eighteen SNPs, a 14 bp insertion/deletion, and 44 haplotypes have been identified in the 3'UTR region (Carosella et al, 2015), which are known to influence the translation of HLA-G proteins through either a reduced transcription, mRNA stability, or aberrant alternative splicing.

The physiologic expression of HLA-G is limited to foetal tissues such as: amniotic cells, erythroid precursors, and cytotrophoblasts, and, in adults, to immune-privileged organs, including the cornea, thymus, pancreatic islets, endothelial cell precursors, and erythroblasts (Carosella et al, 2008). Dendritic cells and macrophages can also express HLA-G. HLA-G can be generated by alternative splicing of primary transcript membrane-bound (HLA-G1 to -G4) and soluble (HLA-G5 to -G7) isoforms (Fig. 1) (Ishitani et al, 1992, Kirszenbaum et al, 1994). Four isoforms - HLA-G1, $-\mathrm{G} 2,-\mathrm{G} 3$, and -G4 have transmembrane and cytoplasmic domains and are, therefore, membrane bound. HLA-G5 is the soluble counterpart of HLA-G1, whereas HLA-G6 is the soluble counterpart of HLA-G2 (Carosella et al, 2008). They are comprised of a heavy chain consisting of three globular domains $(\alpha 1, \alpha 2$, and $\alpha 3)$ which are non-covalently bound to a nanopeptide and $\beta 2$-microglobulin $(\beta 2 \mathrm{~m})$ (Carosella et al, 2008).

HLA-G induces tolerance by inhibiting different cells (Fig. 2). This main function is mediated by binding of both soluble and membrane-bound HLA-G to inhibitory receptors. These inhibitory receptors include immunoglobulin-like transcript (ILT) receptor 2 (CD85j; LILRB1) appearing on lymphoid and myelomonocytic cells, ILT-4 (CD85d; LILRB2) expressed by dendritic cells (DC), macrophages, and monocytes (Fons et al, 2006, Gao et al, 2000, Lopez-Botet et al, 1999), and the killer cell immunoglobulin-like receptor (KIR) 2DL4/p49 (CD158d) expressed by natural killer (NK) cells (Yan et al, 2005). HLA-G directly influences different stages of the immune response, including differentiation, proliferation, cytolysis, or cytokine secretion. In the peripheral blood of cancer patients, HLA-G antigens can also be expressed by tumour-infiltrating immune cells (Pangault et al, 2002, Urosevic et al, 2002, Wagner et al, 2000). HLA-G may impair the immune response of patients against tumour. The function of $\mathrm{CD}^{+} \mathrm{T}$ cells can be inhibited by the HLA-G ${ }^{+}$APC (antigen presenting cell) complex, which then induces their differentiation into regulatory $\mathrm{T}$ cells (Treg) (LeMaoult et al, 2004). HLA-G can also exert an immune-suppressive activity; specifically it can induce the expression of the non-classical HLA class I molecule HLA-E, which binds peptides derived from HLA-G. This molecule sometimes interacts with the inhibitory receptor CD94/NKG2A to block NK and Tcell reactivity (Gooden et al, 2012). Through the use of inhibitory receptors, HLA-G1 isoform also impedes the cytolytic function of uterine and peripheral NK cells (Rouas-Freiss et al, 1997, RouasFreiss et al, 1997). In additional studies, HLA-G was shown to inhibit the function of cytotoxic T lymphocytes (CTL), through a direct interaction with ILT2 or ILT4 inhibitory receptors (Fons et al, 2006, Gao et al, 2000, Lopez-Botet et al, 1999). Recently, 


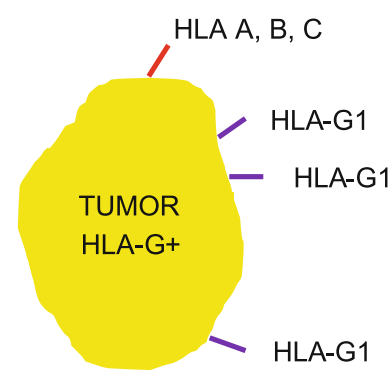

HLA-G5

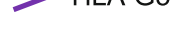

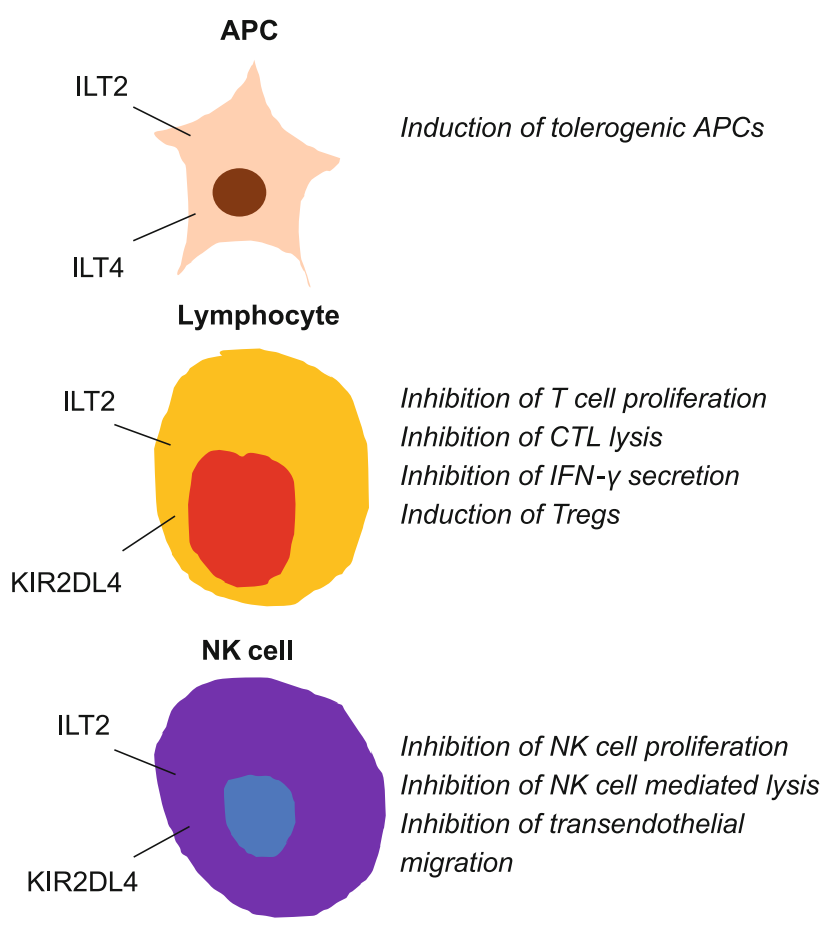

Fig. 2. Mechanisms of both membrane-bound and soluble HLA-G-mediated immune suppression in tumour immune evasion.

new evidence has demonstrated the binding of HLA-G to ILT-2 receptor to suppress B cell responses (Naji et al, 2014). Soluble HLA-G can induce apoptosis of NK cells and cytotoxic T cells, whereas soluble and membrane-bound HLA-G can influence both the expression and release of IFN- $\gamma$ by NK cells (Rajagopalan et al, 2006, van der Meer et al, 2004, van der Meer et al, 2007). It also contains anti-angiogenic functionality by binding to CD160 on endothelial cells (Fons et al, 2006).

\section{Soluble form of HLA-G - origin, structure, and function}

The structure of the soluble and membrane bound isoforms differs at the C-terminus. A short hydrophilic tail replaces the extracellular domain and the intracytoplasmic tail in the secreted isoforms (Fujii et al, 1994, Ishitani et al, 1992, Kirszenbaum et al, 1994). These differences could serve as a marker to distinguish shed or proteolytically cleaved HLA-G isoforms from secreted HLA-G isoforms.

Soluble HLA-G1 was observed to inhibit the cytotoxic activity of HLA class I antigen restricted CTL (Contini et al, 2003, Le Gal et al, 1999, Rouas-Freiss et al, 1999), and sHLA-G5 was observed to inhibit $\mathrm{CD}^{+}$and $\mathrm{CD} 8^{+} \mathrm{T}$ cell alloproliferation by blocking a cell cycle progression. However, sHLA-G5 does not induce apoptosis of alloreactive T cells (Bahri et al, 2006).

Under physiological conditions, monocytes/macrophages combined with myeloid and plasmacytoid dendritic cells produce a major part of sHLA-G (Rebmann et al, 2003).

The level of sHLA-G in serum is approximately one order of magnitude below the amount required to induce apoptosis of some cells in vitro, e.g. of $\mathrm{CD}^{+} \mathrm{T}$ cells and $\mathrm{CD} 8^{+} \mathrm{NK}$ cells (Contini et al, 2003). Therefore, probably under physiological conditions, sHLA-G molecules do not play a major role in triggering $\mathrm{CD}^{+}$cell apoptosis. Thus, the potential role of HLA-G in the regulation of the immune response would be restricted to pathological conditions associated with a marked increase of sHLA-G level in blood or in a concrete specific anatomic site.

Soluble HLA-G has also been detected in the plasma/serum of healthy individuals; however, the levels are significantly lower than the levels of other classical HLA class I antigens (Contini et al, 2003), and are influenced by several variables. The gender of the donor has been showed to influence these levels: sHLA-G levels are higher in women than in men (Rudstein-Svetlicky et al, 2007). Furthermore, as previously observed for classical HLA class I antigens (Puppo et al, 1995, Puppo et al, 1997), another important variable is the polymorphism of HLA-G. Healthy individuals carrying the HLA-G*01013 allele or the "null" allele HLA-G*0105N have significantly lower sHLA-G levels than subjects carrying the more frequent HLA-G*01011 and HLA$\mathrm{G}^{*} 01012$ alleles. In addition, subjects with the latter alleles have significantly lower sHLA-G levels than individuals with the HLAG*01041 allele. Polymorphisms in the 3'UTR and the 5'URR of the HLA-G gene may further influence the levels of sHLA-G in plasma/serum (Hviid et al, 2004). Many studies have evaluated the 14-bp ins/del polymorphism in the 3'UTR, and the 14bp insertion was associated with decreased levels of soluble HLA-G (Chen et al,, 2008, Martelli-Palomino et al, 2013, Rousseau et al,, 2003,). Other polymorphisms in the 3'UTR may influence the binding 


\section{9-617}

of specific microRNAs (SNP at position $+3003 \mathrm{C} / \mathrm{T},+3010 \mathrm{C} / \mathrm{G}$, $+3142 \mathrm{G} / \mathrm{C}$, and $+3196 \mathrm{C} / \mathrm{G}$ ) or the mRNA stability by AU-rich elements (SNP at position $+3187 \mathrm{~A} / \mathrm{G}$ ) leading to an impaired expression of HLA-G (Castelli et al,, 2010, Hviid et al,, 2003). Martelli-Palomino et al (2013) found an association of UTR -5, and -7 haplotypes containing $14 \mathrm{bp}$ insertion, $+3142 \mathrm{G}$ and $+3187 \mathrm{~A}$ alleles with a low expression of sHLA-G in a healthy population (Martelli-Palomino et al, 2013). Among the SNPs in the promotor at 5'URR, the -716TT and -201GG genotypes have been associated with high soluble HLA-G levels (Carlini et al, 2013).

Under physiological conditions, sHLA-G levels are increased in serum and amniotic fluid of pregnant women. Hunt et al (Hunt et al, 2000) showed that serum levels of sHLA-G are significantly higher in pregnant women than in non-pregnant women. Furthermore, sHLA-G1 levels are higher in amniotic fluid than in cord serum and maternal serum, and the levels decrease significantly as time to parturition decreases (Hackmon et al, 2004).

Since trophoblast cell invasion and placentogenesis show biological features like those of carcinogenesis, malignant tumour invasion and growth could be mediated by similar cellular pathways (Kurlak et al, 2017). Several studies have shown that the expression of "embryonic" HLA groups (HLA-G, HLA-E, HLA-F) by tumour cells led to a similar inhibition of the innate and adaptive immune system and thus facilitated the tumour immune escape (therapy) (Diepstra et al, 2008, Ibrahim et al, 2001, Kurlak et al, 2017, Paul et al, 1998, Wischhusen et al, 2007).

\section{Soluble HLA-G in cancer}

There exists a consistent evidence in literature that HLA-G represents an important factor in determining prognosis in various types of cancer.

\section{Breast cancer}

Provatopoulou et al (2012) found significantly higher plasma levels of soluble HLA-G in 120 breast cancer (BC) patients, when comparing them to 40 healthy controls. Also, a significantly increased sHLA-G expression was detected in patients with a mixed type of coexisting ductal and lobular breast lesions, as compared to the patients with pure ductal carcinoma or pure lobular neoplasia (Provatopoulou et al, 2012). König et al investigated the use of soluble HLA-G forms as a prognostic marker for predicting the clinical outcome of breast cancer patients being treated with neoadjuvant chemotherapy (NACT). They found that the total and free sHLA-G levels (ExoQuick derived extracellular vesicles fractions) were significantly higher in NACT treated BC patients (n $=154)$, when compared to the healthy controls $(n=16)$. The high levels of sHLA-Gfree were exclusively associated to oestrogen receptor expression before NACT. Importantly, high sHLA-G EV (extracellular vesicles) levels before NACT were associated with a disease progression and the detection of stem cell-like circulating tumour cells, however, high sHLA-Gfree levels indicated an improved clinical outcome. They demonstrated for the first time that different sHLA-G subcomponents had different prognostic impacts on the clinical outcome of NACT treated BC patients (König et al, 2016). Zidi et al (2016) correlated the concentration of sHLA-G in women with breast cancer $(\mathrm{BC})$ to their history of pregnancy and breastfeeding, reporting significant differences in sHLA-G levels between $\mathrm{BC}$ patients with/without breastfeeding experience. In her study, only those patients, who had no history of pregnancy or breastfeeding presented significant increases in sHLA-G and, moreover, she demonstrated that these patients had advanced SBR (ScraffBloom-Richardson grade) III grade of tumour (Zidi et al, 2016). Another study from Jeong et al (2014) demonstrated higher levels of sHLA-G in the breast cancer group $(n=80)$ as compared to the healthy control group $(n=80)$ (Jeong et al, 2014). Interestingly, the Adolf et al, study in 2019 found the opposing results: lower levels of sHLA-G were present in breast cancer patients $(n=75)$ than in the healthy controls $(n=84)$ in Tanzania. Levels of sHLA-G were also significantly lower in mastectomized patients compared to the non-mastectomized patients. However, this study enrolled patients that had previously been treated with chemotherapy or radiotherapy, hormone therapy or a combination, and $81.3 \%$ of these patients had a mastectomy within the past 12 months (Adolf et al, 2019)

\section{Lung cancer}

Ben Amor et al (2016) investigated the influence of HLA-G allelic variants and serum soluble HLA-G (sHLA-G) levels on the risk of non-small-cell lung cancer (NSCLC). Their study found significantly higher serum sHLA-G levels in the patients with NSCLC, particularly in those with advanced disease stages, as compared to the healthy controls (Ben-Amor et al, 2016). Montilla et al (2016) measured the relationship between the level of sHLA-G in bronchoalveolar lavage (BAL) fluid in patients with tumour histological type and overall patient status according to the Karnofsky scale. No correlation was found between soluble HLA-G levels and age, gender, or smoking status. However, a highly significant difference was observed in the levels of sHLA-G in BAL fluid of patients with different histological types of lung cancer, especially in metastatic tumours. The Karnofsky index showed a significant and inverse correlation with the level of sHLA-G in BAL fluid (Montilla et al, 2016).

\section{Gastrointestinal tumours}

Recently, Lázaro-Sánchez et al (2019) compared sHLA-G expression in 20 colorectal (CRC) patients with a control sample of 10 healthy subjects. The results showed significantly higher levels of salivary sHLA-G in patients with CRC than in the healthy controls, and higher salivary levels of sHLA-G were observed also in advanced stage CRC patients than in the patients in earlier stages. A significant correlation was found between the concentration of sHLA-G in the serum and saliva of the analysed samples (Lázaro-Sánchez et al, 2019). In 2018, Farjadian et al, published the results from their research work, in which they evaluated the expression of HLA-G in tumour tissues and the plasma levels of sHLA-G in 82 patients with gastrointestinal cancer. The presence of $H$. pylori genome was investigated in tumour tissues 
from 25 patients with gastric cancer by PCR (polymerase chain reaction) method. There was a significant correlation between an increased sHLA-G level and stage I tumours. Soluble HLA-G levels were above the cut-off value in all the $H$. pylori-positive patients. They concluded that the level of soluble HLA-G could be a useful indicator for the early diagnosis of gastric and colorectal adenocarcinoma (Farjadian et al, 2018). Li et al (2017) showed that plasma sHLA-G levels in 178 colorectal cancer (CRC) patients were significantly increased compared to the normal controls. CRC patients with sHLA-G above median levels had a significantly shorter survival time than those with lower sHLA-G levels. Soluble HLA-G levels provided a significant predictive value for CRC patients specifically from the following groups: females, the elderly, advanced tumour burden, regional lymph node status, both metastasis status and clinical stage (Li et al, 2017). Similarly, Kirana et al (2017) investigated the prognostic value of preoperative plasma sHLA-G in 133 CRC patients. They observed, within the high 33rd percentile of sHLA-G levels, a higher frequency of mucinous carcinoma (MC) patients and higher sHLA-G levels in the patients with vascular invasion. Moreover, MC patients had significantly higher sHLA-G levels compared to those with adenocarcinoma. Only in stage III patients, high sHLA-G levels were associated with a significantly longer liver metastasis free survival (LMFS) time, and sHLA-G levels displayed a positive correlation with LMFS. They conjectured that SHLA-G levels were associated with distinct progression patterns in consecutive disease stages (Kirana et al, 2017). One year earlier (Pan et al, 2016) measured plasma level of sHLA-G in 81 gastric cancer (GC) patients, 53 benign gastric disease patients and 77 normal controls. They showed that plasma levels of sHLA-G were dramatically increased in GC compared with normal controls and benign gastric disease patients. The AUC (area under curve) for sHLA-G was 0.730 greater than serum AFP, CEA, CA125, CA19-9 and CA72-4.

\section{Urogenital cancer}

In 2018, Ben Yahia et al focused on the expression of sHLA-G in endometrial cancer (EC). They examined the total sHLA-G expression, as well as the sHLA-G1 and HLA-G5 isoforms expression in plasma samples from 40 patients and 45 healthy controls. Immunoprecipitation and Coomassie blue staining were performed to explore the presence of plasmatic sHLA-G monomers and dimers. SHLA-G plasma level was significantly increased in the patients with EC compared to the healthy controls. Additionally, HLA-G5 molecules were more represented than sHLA-G1 molecules in EC. Interestingly, sHLA-G has been shown to be elevated in early stages (Stages I and II) of EC, as well as in high grade EC (Grade 3) that is associated with a rapid spread (Ben Yahia et al, 2018). Heidari et al (2017) studied the role of sHLA-G in patients with malignant prostate tumour $(n=26)$, patients with benign prostate tumour $(n=26)$, and a group of healthy men $(n=26)$ and showed that the mean level of sHLA-G was higher in instances of cancer and found a significant difference in SHLA-G serum level between the three groups (Heidari et al, 2017). In contrary,
Szipak-Szmigiel et al (2017) showed that serum and peritoneal fluid concentrations of sHLA-G in ovarian cancer patients had no diagnostic values for differentiating between ovarian malignancies $(n=38)$, benign serous cysts $(n=54)$, and endometriomas ( =43) (Szipak-Szmigiel et al, 2017).

\section{Head and neck cancer}

In 2020, Agnihotri et al published the study that compared sHLA-G in 122 patients with head and neck squamous cell carcinoma and 99 healthy controls. Significantly elevated levels of sHLA-G were observed in the cancer patients compared to the controls (levels decreased in patients in response to therapy (Agnihotri et al, 2020)).

\section{Childhood malignancies Neuroblastoma}

Morandi et al (2016) was the first to analyse the concentration of sHLA-G in bone marrow (BM) plasma samples from neuroblastoma patients $(n=31)$ at the time of their diagnosis and healthy donors $(n=13)$. However, the study found the levels to be similar. In contrast, BM plasma levels of sHLA-G were higher in patients with metastatic disease than in patients with localized neuroblastoma (Morandi et al, 2016).

\section{Leukaemia}

Almeida et al (2018) measured Th1, Th2, Th17 cytokines and soluble HLA-G levels in the bone marrow of 32 Brazilian children on three separate occasions: at the time of diagnosis, after induction of chemotherapy, and after completion of chemotherapy. Increased levels of sHLA-G at time of diagnosis were found to be associated with an increased leukocyte count, which is a well-known factor for poor prognosis (Almeida et al, 2018). Gros et al (2006) pointed out that an increased secretion of sHLA-G seems to be more pronounced in acute leukaemia subtypes affecting monocytic and lymphoid lineages such as FABM4 and FABM5, as well as both B and T acute lymphoblastic leukaemia. Correlations between SHLA-G plasma level and clinical biologic features suggest a link between the elevated sHLA-G level and the absence of anterior myelodysplasia and high-level leucocytosis. (Gros et al, 2006)

\section{Unspecific malignant diseases}

Sun et al (2017) detected soluble HLA-G concentrations in ascites of 94 patients ( 64 with malignant and 30 with benign ascites). Ascitic levels of sHLA-G were significantly higher in malignant ascites group than in the group of benign ascites. The detection of ascitic soluble human leukocyte antigen-G was deemed a good predictor for distinguishing between the malignant and benign ascites, particularly in cases that are cytology-negative and biopsypositive (Sun et al, 2017). 
609-617

\section{Conclusion}

Many studies have highlighted the function of the HLA-G gene (and corresponding molecule) as a diagnostic and prognostic factor for cancer patients' clinical outcome. HLA-G has been promoted as a promising immunotherapy target. International recommended standardization protocols, larger cohorts, and prospective studies are required to confirm and validate HLA-G as a target before routine clinical application. Furthermore, in addition to the seven well-known HLA-G isoforms, novel unrecognized HLA-G isoforms do exist. However, as shown in this review, soluble HLA-G is elevated in most cancer patients, when compared to the healthy subjects. Serum/plasma/fluid specimens can be obtained easily and quickly and could aid in the differential diagnosis.

\section{References}

1. McMaster MT, Librach CL, Zhou Y et al. Human placental HLA$\mathrm{G}$ expression is restricted to differentiated cytotrophoblasts. J Immunol 1995; 154 (8): 3771-3778.

2. Carosella ED, Favier B, Rouas-Freiss N, Moreau P, Lemaoult J. Beyond the increasing complexity of the immunomodulatory HLA-G molecule. Blood 2008; 111 (10): 4862-4870. DOI: 10.1182/ blood-2007-12-127662.

3. Wagner SN, Rebmann V, Willers CP, Grosse-Wilde H, Goos M. Expression analysis of classic and non-classic HLA molecules before interferon alfa-2b treatment of melanoma. Lancet 2000; 356 (9225): 220-221. DOI: 10.1016/S0140-6736 (00)02486-7.

4. Degenhardt Y, Huang J, Greshock J et al. Distinct MHC gene expression patterns during progression of melanoma. Genes Chromosomes Cancer 2010; 49 (2): 144-154. DOI: 10.1002/gcc.20728.

5. Bezuhly M, Howlett A, Colp P et al. Quantitative HLA-G expression in metastasising and non-metastasising primary thin cutaneous melanomas. Dermatology 2008; 217 (3): 281-283. DOI: 10.1159/000150602.

6. Paul P, Cabestré FA, Le Gal FA et al. Heterogeneity of HLA-G gene transcription and protein expression in malignant melanoma biopsies. Cancer Res 1999; 59 (8): 1954-1960.

7. Paul P, Rouas-Freiss N, Khalil-Daher I et al. HLA-G expression in melanoma: a way for tumor cells to escape from immunosurveillance. Proc Natl Acad Sci USA 1998; 95 (8): 4510-4515. DOI: 10.1073/pnas.95.8.4510

8. Ghandri N, Gabbouj S, Farhat K et al. Association of HLA-G polymorphisms with nasopharyngeal carcinoma risk and clinical outcome. Hum Immunol 2011; 72 (2): 150-158. DOI: 10.1016/j.humimm.2010.10.006.

9. Dardano A, Rizzo R, Polini A et al. Soluble human leukocyte antigen$\mathrm{g}$ and its insertion/deletion polymorphism in papillary thyroid carcinoma: novel potential biomarkers of disease? J Clin Endocrinol Metab 2012; 97 (11): 4080-4086. DOI: $10.1210 /$ jc.2012-2231.

10. Nunes LM, Ayres FM, Francescantonio IC et al. Association between the HLA-G molecule and lymph node metastasis in papillary thyroid cancer. Hum Immunol 2013; 74 (4): 447-451. DOI: 10.1016/j.humimm.2012.12.012.

11. Fan X, Wang $\mathbf{Y}$, Zhang $\mathbf{C}$ et al. Human leukocyte antigen-G overexpression predicts poor clinical outcomes in low-grade gliomas. J Neuroimmunol 2016; 294: 27-31. DOI: 10.1016/j.jneuroim.2016.03.015.
12. Kren L, Muckova K, Lzicarova E et al. Production of immune-modulatory nonclassical molecules HLA-G and HLA-E by tumor infiltrating ameboid microglia/macrophages in glioblastomas: a role in innate immunity? J Neuroimmunol 2010; 220 (1-2): 131-135. DOI: 10.1016/j.jneuroim.2010.01.014.

13. Kren L, Slaby O, Muckova $\mathrm{K}$ et al. Expression of immune-modulatory molecules HLA-G and HLA-E by tumor cells in glioblastomas: an unexpected prognostic significance? Neuropathology 2011; 31 (2): 129-134. DOI: 10.1111/j.1440-1789.2010.01149.x.

14. Wastowski IJ, Simões RT, Yaghi L et al. Human leukocyte antigen$\mathrm{G}$ is frequently expressed in glioblastoma and may be induced in vitro by combined 5-aza-2'-deoxycytidine and interferon- $\gamma$ treatments: results from a multicentric study. Am J Pathol 2013; 182 (2): 540-552. DOI: 10.1016/j. ajpath.2012.10.021.

15. Wiendl H, Mitsdoerffer M, Hofmeister $V$ et al. A functional role of HLA-G expression in human gliomas: an alternative strategy of immune escape. J Immunol 2002; 168 (9): 4772-4780. DOI: 10.4049/jimmunol.168.9.4772.

16. Wischhusen J, Waschbisch A, Wiendl H. Immune-refractory cancers and their little helpers - an extended role for immunetolerogenic MHC molecules HLA-G and HLA-E? Semin Cancer Biol 2007; 17 (6): 459-468. DOI: 10.1016/j.semcancer.2007.07.005.

17. Yie SM, Yang H, Ye SR, Li K, Dong DD, Lin XM. Expression of human leucocyte antigen G (HLA-G) is associated with prognosis in nonsmall cell lung cancer. Lung Cancer 2007; 58 (2): 267-274. DOI: 10.1016/j. lungcan.2007.06.011.

18. Montilla D, Pérez M, Borges L, Bianchi G, Cova JA. Soluble Human Leukocyte Antigen-G in the Bronchoalveolar Lavage of Lung Cancer Patients. Antígeno leucocitario humano-G soluble en el lavado broncoalveolar de pacientes con cáncer pulmonar. Arch Bronconeumol 2016; 52 (8): 420-424. DOI: 10.1016/j.arbres.2016.01.019.

19. Urosevic M, Kurrer MO, Kamarashev J et al. Human leukocyte antigen $\mathrm{G}$ up-regulation in lung cancer associates with high-grade histology, human leukocyte antigen class I loss and interleukin-10 production. Am J Pathol 2001; 159 (3): 817-824. DOI: 10.1016/S0002-9440 (10)61756-7.

20. Wiśniewski A, Kowal A, Wyrodek E et al. Genetic polymorphisms and expression of HLA-G and its receptors, KIR2DL4 and LILRB1, in non-small cell lung cancer. Tissue Antigens 2015; 85 (6): 466-475. DOI: 10.1111/tan.12561.

21. Yan WH, Liu D, Lu HY, Li YY, Zhang X, Lin A. Significance of tumour cell HLA-G5/-G6 isoform expression in discrimination for adenocarcinoma from squamous cell carcinoma in lung cancer patients. J Cell Mol Med 2015; 19 (4): 778-785. DOI: 10.1111/jcmm. 12400.

22. Zhang Y, Zhao J, Qiu L et al. Co-expression of ILT4/HLA-G in human non-small cell lung cancer correlates with poor prognosis and ILT4HLA-G interaction activates ERK signaling. Tumour Biol 2016; 37 (8): 11187-11198. DOI: 10.1007/s13277-016-5002-5.

23. Li XJ, Zhang X, Lin A, Ruan YY, Yan WH. Human leukocyte antigen-G (HLA-G) expression in cervical cancer lesions is associated with disease progression. Hum Immunol 2012; 73 (9): 946-949. DOI: 10.1016/j. humimm.2012.07.041.

24. Zhang X, Han QY, Li JB, Ruan YY, Yan WH, Lin A. Lesion HLAG5/-G6 isoforms expression in patients with ovarian cancer. Hum Immunol 2015; 77 (9): 780-784. DOI: 10.1016/j.humimm.2015.12.003.

25. Rutten MJ, Dijk F, Savci-Heijink CD et al. HLA-G expression is an independent predictor for improved survival in high grade ovarian carcinomas. J Immunol Res 201; 274584. DOI: 10.1155/2014/274584 . 
26. Lin A, Xu HH, Xu DP, Zhang X, Wang Q, Yan WH. Multiple steps of HLA-G in ovarian carcinoma metastasis: alter NK cytotoxicity and induce matrix metalloproteinase-15 (MMP-15) expression. Hum Immunol 203; 74 (4): 439-446. DOI: 10.1016/j.humimm.2012.11.021.

27. Bijen CB, Bantema-Joppe EJ, de Jong RA et al. The prognostic role of classical and nonclassical MHC class I expression in endometrial cancer. Int J Cancer 2010; 126 (6): 1417-1427. DOI: 10.1002/ijc.24852.

28. Gimenes F, Teixeira JJ, de Abreu AL, Souza RP, Pereira MW, da Silva VR et al. Human leukocyte antigen (HLA-F)-G and cervical cancer immunoediting: A candidate molecule for therapeutic intervention and prognostic biomarker? Biochim Biophys Acta 2014; 1846: 576-589.

29. Rodríguez JA, Galeano L, Palacios DM et al. Altered HLA class I and HLA-G expression is associated with IL-10 expression in patients with cervical cancer. Pathobiology 2012; 79 (2): 72-83. DOI: 10.1159/000334089.

30. Zheng N, Wang CX, Zhang X et al. Up-regulation of HLA-G expression in cervical premalignant and malignant lesions. Tissue Antigens 2011; 77 (3): 218-224. DOI: 10.1111/j.1399-0039.2010.01607.x.

31. Langat DK, Sue Platt J, Tawfik O, Fazleabas AT, Hunt JS. Differential expression of human leukocyte antigen-G (HLA-G) messenger RNAs and proteins in normal human prostate and prostatic adenocarcinoma. $\mathrm{J}$ Reprod Immunol 2006; 71 (1): 75-86. DOI: 10.1016/j.jri.2006.01.006.

32. Tronik-Le Roux D, Renard $\mathbf{J}$, Vérine $\mathbf{J}$ et al. Novel landscape of HLA-G isoforms expressed in clear cell renal cell carcinoma patients. Mol Oncol 2017; 11 (11): 1561-1578. DOI: 10.1002/1878-0261.12119.

33. Ibrahim EC, Guerra N, Lacombe MJ et al. Tumor-specific upregulation of the nonclassical class I HLA-G antigen expression in renal carcinoma. Cancer Res 2001; 61 (18): 6838-6845.

34. Hanak L, Slaby O, Lauerova L, Kren L, Nenutil R, Michalek J. Expression pattern of HLA class I antigens in renal cell carcinoma and primary cell line cultures: methodological implications for immunotherapy. Med Sci Monit 2009; 15 (12): CR638-CR643.

35. Lin A, Zhang X, Zhou WJ et al. Human leukocyte antigen-G expression is associated with a poor prognosis in patients with esophageal squamous cell carcinoma. Int J Cancer 2011; 129 (6): 1382-1390. DOI: 10.1002/ijc. 25807 .

36. Zhu CB, Wang CX, Zhang X, Zhang J, Li W. Serum sHLA-G levels: a useful indicator in distinguishing colorectal cancer from benign colorectal diseases. Int J Cancer 2011; 128 (3): 617-622. DOI: 10.1002/ijc.25372.

37. Swets M, König MH, Zaalberg A et al. HLA-G and classical HLA class I expression in primary colorectal cancer and associated liver metastases. Hum Immunol 2016; 77 (9): 773-779. DOI: 10.1016/j.humimm.2016.03.001.

38. Guo ZY, Lv YG, Wang L et al. Predictive value of HLA-G and HLA$\mathrm{E}$ in the prognosis of colorectal cancer patients. Cell Immunol 2015; 293 (1): 10-16. DOI: 10.1016/j.cellimm.2014.10.003.

39. Reimers MS, Engels CC, Putter $\mathbf{H}$ et al. Prognostic value of HLA class I, HLA-E, HLA-G and Tregs in rectal cancer: a retrospective cohort study. BMC Cancer 14:486. Published 2014 July 5. DOI: 10.1186/14712407-14-486.

40. Zeestraten EC, Reimers MS, Saadatmand S et al. Combined analysis of HLA class I, HLA-E and HLA-G predicts prognosis in colon cancer patients Br J Cancer 2014; 110 (2): 459-468. DOI: 10.1038/bjc.2013.696.

41. Cao M, Yie SM, Liu J, Ye SR, Xia D, Gao E. Plasma soluble HLA-G is a potential biomarker for diagnosis of colorectal, gastric, esophageal and lung cancer. Tissue Antigens 2011; 78 (2): 120-128. DOI: 10.1111/j.13990039.2011.01716.x.
42. de Kruijf EM, Sajet A, van Nes JG et al. HLA-E and HLA-G expression in classical HLA class I-negative tumors is of prognostic value for clinical outcome of early breast cancer patients. J Immunol 2010; 185 (12): 7452-7459. DOI: 10.4049/jimmunol.1002629.

43. Jeong S, Park S, Park BW, Park Y, Kwon OJ, Kim HS. Human leukocyte antigen-G (HLA-G) polymorphism and expression in breast cancer patients. PLoS One 2014; 9 (5): e98284. Published 2014 May 28. DOI: 10.1371/journal.pone.0098284.

44. Rolfsen GB, Castelli EC, Donadi EA, Duarte RA, Soares CP. HLA-G polymorphism and breast cancer. Int J Immunogenet 2014; 41 (2): 143-148. DOI: 10.1111/iji.12092.

45. da Silva GB, Silva TG, Duarte RA et al. Expression of the Classical and Nonclassical HLA Molecules in Breast Cancer. Int J Breast Cancer 2013: 250435. DOI: 10.1155/2013/250435.

46. He X, Dong DD, Yie SM et al. HLA-G expression in human breast cancer: implications for diagnosis and prognosis, and effect on allocytotoxic lymphocyte response after hormone treatment in vitro. Ann Surg Oncol 2010; 17 (5): 1459-1469. DOI: 10.1245/s10434-009-0891-9.

47. Kleinberg L, Flørenes VA, Skrede M et al. Expression of HLA-G in malignant mesothelioma and clinically aggressive breast carcinoma. Virchows Arch 2006; 449 (1): 31-39. DOI: 10.1007/s00428-005-0144-7.

48. Palmisano GL, Pistillo MP, Fardin $P$ et al. Analysis of HLA-G expression in breast cancer tissues. Hum Immunol 2002; 63 (11): 969-976. DOI: 10.1016/s0198-8859 (02)00642-0.

49. Ferguson R, Ramanakumar AV, Koushik A et al. Human leukocyte antigen $\mathrm{G}$ polymorphism is associated with an increased risk of invasive cancer of the uterine cervix. Int J Cancer 2012; 131 (3): E312-E319. DOI: 10.1002/ijc. 27356 .

50. Singer G, Rebmann V, Chen YC et al. HLA-G is a potential tumor marker in malignant ascites. Clin Cancer Res 2003; 9 (12): 4460-4464.

51. Nückel H, Rebmann V, Dürig J, Dührsen U, Grosse-Wilde H. HLA$\mathrm{G}$ expression is associated with an unfavorable outcome and immunodeficiency in chronic lymphocytic leukemia. Blood 2005; 105 (4): 1694-1698. DOI: 10.1182/blood-2004-08-3335.

52. Almeida RDS, Ramos AML, Luna CF et al. Cytokines and soluble HLA-G levels in bone marrow stroma and their association with the survival rate of patients exhibiting childhood T-cell acute lymphoblastic leukemia. Cytokine 2018; 102: 94-101. DOI: 10.1016/j.cyto.2017.07.014.

53. Xu YP, Wieten L, Wang SX et al. Clinical significance of HLA-E genotype and surface/soluble expression levels between healthy individuals and patients with acute leukemia. Leuk Lymphoma 2019; 60 (1): 208-215. DOI: 10.1080/10428194.2018.1474521.

54. Bielska M, Bojo M, Klimkiewicz-Wojciechowska G et al. Human leukocyte antigen-G polymorphisms influence the clinical outcome in diffuse large B-cell lymphoma. Genes Chromosomes Cancer 2015; 54 (3): 185-93.

55. Urosevic M, Willers J, Mueller B, Kempf W, Burg G, Dummer R. HLA-G protein up-regulation in primary cutaneous lymphomas is associated with interleukin-10 expression in large cell T-cell lymphomas and indolent B-cell lymphomas. Blood 2002; 99 (2): 609-617. DOI: 10.1182/ blood.v99.2.609.

56. Diepstra A, Poppema S, Boot $\mathbf{M}$ et al. HLA-G protein expression as a potential immune escape mechanism in classical Hodgkin's lymphoma. Tissue Antigens 2008; 71 (3): 219-226. DOI: 10.1111/j.13990039.2008.01005.x. 
609-617

57. Amiot L, Ferrone S, Grosse-Wilde H, Seliger B. Biology of HLA-G in cancer: a candidate molecule for therapeutic intervention?. Cell Mol Life Sci 2011; 68 (3): 417-431. DOI: 10.1007/s00018-010-0583-4.

58. Yan WH, Lin A, Chen BG et al. Unfavourable clinical implications for HLA-G expression in acute myeloid leukaemia. J Cell Mol Med 2008; 12 (3): 889-898. DOI: 10.1111/j.1582-4934.2008.00175.x.

59. Curigliano G, Criscitiello C, Gelao L, Goldhirsch A. Molecular pathways: human leukocyte antigen G (HLA-G). Clin Cancer Res 2013; 19 (20): 5564-5571. DOI: 10.1158/1078-0432.CCR-12-3697.

60. Carosella ED, Rouas-Freiss N, Tronik-Le Roux D, Moreau P, LeMaoult J. HLA-G: An Immune Checkpoint Molecule. Adv Immunol 2015; 127: 33-144. DOI: 10.1016/bs.ai.2015.04.001.

61. Robinson J, Halliwell JA, Hayhurst JD, Flicek P, Parham P, Marsh SG. The IPD and IMGT/HLA database: allele variant databases. Nucleic Acids Res 2015; 43 (Database issue): D423-D431. DOI: 10.1093/nar/ gku1161.

62. Castelli EC, Veiga-Castelli LC, Yaghi L, Moreau P, Donadi EA. Transcriptional and posttranscriptional regulations of the HLA-G gene. J Immunol Res 2014: 734068. DOI: 10.1155/2014/734068.

63. Donadi EA, Castelli EC, Arnaiz-Villena A, Roger M, Rey D, Moreau P. Implications of the polymorphism of HLA-G on its function, regulation, evolution and disease association. Cell Mol Life Sci 2011; 68 (3): 369-395. DOI: 10.1007/s00018-010-0580-7.

64. Ishitani A, Geraghty DE. Alternative splicing of HLA-G transcripts yields proteins with primary structures resembling both class I and class II antigens. Proc Natl Acad Sci USA 1992; 89 (9): 3947-3951. DOI: 10.1073/ pnas.89.9.3947.

65. Kirszenbaum M, Moreau P, Gluckman E, Dausset J, Carosella E. An alternatively spliced form of HLA-G mRNA in human trophoblasts and evidence for the presence of HLA-G transcript in adult lymphocytes. Proc Natl Acad Sci USA 1994; 91 (10): 4209-4213. DOI: 10.1073/ pnas.91.10.4209.

66. Fons P, Chabot S, Cartwright JE et al. Soluble HLA-G1 inhibits angiogenesis through an apoptotic pathway and by direct binding to CD160 receptor expressed by endothelial cells. Blood 2006; 108 (8): 2608-2615. DOI: 10.1182/blood-2005-12-019919.

67. Gao GF, Willcox BE, Wyer JR et al. Classical and nonclassical class I major histocompatibility complex molecules exhibit subtle conformational differences that affect binding to CD8alphaalpha. J Biol Chem 2000; 275 (20): 15232-15238. DOI: 10.1074/jbc.275.20.15232.

68. López-Botet M, Navarro F, Llano M. How do NK cells sense the expression of HLA-G class Ib molecules? Semin Cancer Biol 1999; (1): 19-26. DOI: 10.1006/scbi.1998.0107.

69. Yan WH, Fan LA. Residues Met76 and Gln79 in HLA-G alpha1 domain involve in KIR2DL4 recognition. Cell Res 2005; 15 (3): 176-182. DOI: $10.1038 /$ sj.cr.7290283.

70. Pangault C, Le Friec G, Caulet-Maugendre S et al. Lung macrophages and dendritic cells express HLA-G molecules in pulmonary diseases. Hum Immunol 2002; 63 (2): 83-90. DOI: 10.1016/s0198-8859 (01)00373-1.

71. LeMaoult J, Krawice-Radanne I, Dausset J, Carosella ED. HLA-G1-expressing antigen-presenting cells induce immunosuppressive CD4+ T cells. Proc Natl Acad Sci USA 2004; 101 (18): 7064-7069. DOI: 10.1073/pnas.0401922101.

72. Gooden MJ, van Hall T. Infiltrating CTLs are bothered by HLA-E on tumors. Oncoimmunology 2012; 1 (1): 92-93. DOI: 10.4161/onci.1.1.17961.
73. Rouas-Freiss N, Gonçalves RM, Menier C, Dausset J, Carosella ED. Direct evidence to support the role of HLA-G in protecting the fetus from maternal uterine natural killer cytolysis. Proc Natl Acad Sci USA 1997; 94 (21): 11520-11525. DOI: 10.1073/pnas.94.21.11520.

74. Rouas-Freiss N, Marchal RE, Kirszenbaum M, Dausset J, Carosella ED. The alpha1 domain of HLA-G1 and HLA-G2 inhibits cytotoxicity induced by natural killer cells: is HLA-G the public ligand for natural killer cell inhibitory receptors? Proc Natl Acad Sci USA 1997; 94 (10): 5249-5254. DOI: 10.1073/pnas.94.10.5249.

75. Naji A, Menier C, Morandi F et al. Binding of HLA-G to ITIM-bearing Ig-like transcript 2 receptor suppresses B cell responses. J Immunol 2014; 192 (4): 1536-1546. DOI: 10.4049/jimmunol.1300438.

76. Rajagopalan S, Bryceson YT, Kuppusamy SP et al. Activation of NK cells by an endocytosed receptor for soluble HLA-G. PLoS Biol 2006; 4 (1): e9. DOI: 10.1371/journal.pbio.0040009.

77. van der Meer A, Lukassen HG, van Lierop MJ et al. Membranebound HLA-G activates proliferation and interferon-gamma production by uterine natural killer cells. Mol Hum Reprod 2004; 10 (3): 189-195. DOI: $10.1093 / \mathrm{molehr} / \mathrm{gah} 032$.

78. van der Meer A, Lukassen HG, van Cranenbroek B et al. Soluble HLA-G promotes Th1-type cytokine production by cytokine-activated uterine and peripheral natural killer cells. Mol Hum Reprod 2007; 13 (2): 123-133. DOI: 10.1093/molehr/gal100.

79. Fujii T, Ishitani A, Geraghty DE. A soluble form of the HLA-G antigen is encoded by a messenger ribonucleic acid containing intron 4 . $\mathrm{J}$ Immunol 1994; 153 (12): 5516-5524.

80. Rebmann V, Busemann A, Lindemann M, Grosse-Wilde H. Detection of HLA-G5 secreting cells. Hum Immunol 2003; 64 (11): 1017-1024. DOI: 10.1016/j.humimm.2003.08.354.

81. Contini P, Ghio M, Poggi A et al. Soluble HLA-A,-B,-C and -G molecules induce apoptosis in T and NK CD8+ cells and inhibit cytotoxic T cell activity through CD8 ligation. Eur J Immunol 2003; 33 (1): 125-134. DOI: $10.1002 / \mathrm{immu} .200390015$.

82. Rudstein-Svetlicky N, Loewenthal R, Horejsi V, Gazit E. HLA-G levels in serum and plasma. Tissue Antigens 2007; 69 Suppl 1: 140-142. DOI: 10.1111/j.1399-0039.2006.763_4.x.

83. Puppo F, Scudeletti M, Indiveri F, Ferrone S. Serum HLA class I antigens: markers and modulators of an immune response?Immunol Today 1995; 16 (3): 124-127. DOI: 10.1016/0167-5699 (95)80127-8.

84. Puppo F, Indiveri F, Scudeletti M, Ferrone S. Soluble HLA antigens: new roles and uses. Immunol Today 1997; 18 (4): 154-155. DOI: 10.1016/ s0167-5699 (97)84660-9.

85. Hviid TV, Rizzo R, Christiansen OB, Melchiorri L, Lindhard A, Baricordi OR. HLA-G and IL-10 in serum in relation to HLA-G genotype and polymorphisms. Immunogenetics 2004; 56 (3): 135-141. DOI: 10.1007/s00251-004-0673-2.

86. Le Gal FA, Riteau B, Sedlik C et al. HLA-G-mediated inhibition of antigen-specific cytotoxic T lymphocytes. Int Immunol 1999; 11 (8): 1351-1356. DOI: 10.1093/intimm/11.8.1351.

87. Rouas-Freiss N, Khalil-Daher I, Riteau B et al. The immunotolerance role of HLA-G. Semin Cancer Biol 1999; 9 (1): 3-12. DOI: 10.1006/ scbi.1998.0103.

88. Bahri R, Hirsch F, Josse A et al. Soluble HLA-G inhibits cell cycle progression in human alloreactive T lymphocytes. J Immunol 2006; 176 (3): 1331-1339. DOI: 10.4049/jimmunol.176.3.1331. 
89. Hunt JS, Jadhav L, Chu W, Geraghty DE, Ober C. Soluble HLA$\mathrm{G}$ circulates in maternal blood during pregnancy. Am J Obstet Gynecol 2000; 183 (3): 682-688. DOI: 10.1067/mob.2000.106762.

90. Hackmon R, Hallak M, Krup M et al. HLA-G antigen and parturition: maternal serum, fetal serum and amniotic fluid levels during pregnancy. Fetal Diagn Ther 2004; 19 (5): 404 409. DOI: 10.1159/000078992.

91. Kurlak LO, Knöfler M, Mistry HD. Lumps \& Bumps: Common features between placental development and cancer growth. Placenta 2017; 56: 2-4. DOI: 10.1016/j.placenta.2017.04.012.

92. Zeestraten EC, Reimers MS, Saadatmand $S$ et al. Combined analysis of HLA class I, HLA-E and HLA-G predicts prognosis in colon cancer patients [published correction appears in Br J Cancer 2014; 111 (12): 2383.

93. Goossens-Beumer, Inès $\mathbf{J}$ [added]]. Br J Cancer 2014; 110 (2): 459-468. DOI: 10.1038/bjc.2013.696.

94. Provatopoulou X, Kalogera E, Sagkriotis A et al. Soluble human leukocyte antigen-G expression in patients with ductal and lobular breast malignancy. Anticancer Res 2012; 32 (3): 1021-1026.

95. König L, Kasimir-Bauer S, Hoffmann $O$ et al. The prognostic impact of soluble and vesicular HLA-G and its relationship to circulating tumor cells in neoadjuvant treated breast cancer patients. Hum Immunol 2016; 77 (9): 791-799. DOI: 10.1016/j.humimm.2016.01.002.

96. Zidi I, Kharrat N, Sebai R et al. Pregnancy and breastfeeding: a new theory for sHLA-G in breast cancer patients?. Immunol Res 2016; 64 (2): 636-639. DOI: 10.1007/s12026-015-8764-8.

97. Ben Amor A, Beauchemin K, Faucher MC, Hamzaoui A, Hamzaoui K, Roger M. Human Leukocyte Antigen G Polymorphism and Expression Are Associated with an Increased Risk of Non-Small-Cell Lung Cancer and Advanced Disease Stage. PLoS One 2016; 11 (8): e0161210. Published 2016 Aug 12. DOI: 10.1371/journal.pone.0161210.

98. Lázaro-Sánchez AD, Salces-Ortiz P, Velásquez LI, Orozco-Beltrán D, Díaz-Fernández N, Juárez-Marroquí A. HLA-G as a new tumor biomarker: detection of soluble isoforms of HLA-G in the serum and saliva of patients with colorectal cancer. Clin Transl Oncol 2020; 22 (7): 1166-1171. DOI: 10.1007/s12094-019-02244-2.

99. Farjadian S, Tabebordbar M, Mokhtari M, Safaei A, Malekzadeh M, Ghaderi A. HLA-G Expression in Tumor Tissues and Soluble HLA-G Plasma Levels in Patients with Gastrointestinal Cancer. Asian Pac J Cancer Prev 2018; 19 (10): 2731-2735. DOI: 10.22034/APJCP.2018.19.10.2731.

100. Li JB, Ruan YY, Hu B et al. Importance of the plasma soluble HLA-G levels for prognostic stratification with traditional prognosticators in colorectal cancer. Oncotarget 2017; 8 (30): 48854-48862. DOI: 10.18632/oncotarget. 1645 .

101. Kirana C, Ruszkiewicz A, Stubbs RS et al. Soluble HLA-G is a differential prognostic marker in sequential colorectal cancer disease stages. Int J Cancer 2017; 140 (11): 2577-2586. DOI: 10.1002/ijc.30667.

102. Pan YQ, Ruan YY, Peng JB et al. Diagnostic significance of soluble human leukocyte antigen-G for gastric cancer. Hum Immunol 2016; 77 (4): 317-324. DOI: 10.1016/j.humimm.2016.01.009.

103. Ben Yahia $H$, Babay W, Bortolotti $D$ et al. Increased plasmatic soluble HLA-G levels in endometrial cancer. Mol Immunol 2018; 99 : 82-86. DOI: 10.1016/j.molimm.2018.04.007.

104. Heidari MH, Movafagh A, Abdollahifar MA et al. Evaluation of sHLA-G levels in serum of patients with prostate cancer identify as a potential of tumor marker Anat Cell Biol 2017; 50 (1): 69-72. DOI: 10.5115/ acb.2017.50.1.69.
105. Sipak-Szmigiel O, Włodarski P, Ronin-Walknowska E et al. Serum and peritoneal fluid concentrations of soluble human leukocyte antigen, tumor necrosis factor alpha and interleukin 10 in patients with selected ovarian pathologies. J Ovarian Res 2017; 10 (1): 25. DOI: 10.1186/ s13048-017-0320-9.

106. Morandi F, Pozzi S, Carlini B, Amoroso L, Pistoia V, Corrias MV. Soluble HLA-G and HLA-E Levels in Bone Marrow Plasma Samples Are Related to Disease Stage in Neuroblastoma Patients. J Immunol Res 2016: 7465741. DOI: 10.1155/2016/7465741.

107. Sun J, Chang YX, Niu CY. Evaluation of ascitic soluble human leukocyte antigen-G for distinguishing malignant ascites from benign ascites. Tumour Biol 2017; 39 (11): 1010428317726840. DOI: $10.1177 / 1010428317726840$.

108. Rousseau P, Le Discorde M, Mouillot G, Marcou C, Carosella ED, Moreau P. The 14 bp deletion-insertion polymorphism in the 3' UT region of the HLA-G gene influences HLA-G mRNA stability. Hum Immunol 2003; 64 (11): 1005-1010. DOI: 10.1016/j.humimm.2003.08.347.

109. Chen XY, Yan WH, Lin A, Xu HH, Zhang JG, Wang XX. The 14 bp deletion polymorphisms in HLA-G gene play an important role in the expression of soluble HLA-G in plasma. Tissue Antigens 2008; 72 (4): 335-341. DOI: 10.1111/j.1399-0039.2008.01107.x.

110. Martelli-Palomino G, Pancotto JA, Muniz YC et al. Polymorphic sites at the 3' untranslated region of the HLA-G gene are associated with differential hla-g soluble levels in the Brazilian and French population. PLoS One 2013; 8 (10): e71742. DOI: 10.1371/journal.pone.0071742.

111. Castelli EC, Mendes-Junior CT, Deghaide NH et al. The genetic structure of 3'untranslated region of the HLA-G gene: polymorphisms and haplotypes. Genes Immun 2010; 11 (2): 134-141. DOI: 10.1038/ gene.2009.74

112. Hviid TV, Hylenius S, Rorbye C, Nielsen LG. HLA-G allelic variants are associated with differences in the HLA-G mRNA isoform profile and HLA-G mRNA levels. Immunogenetics 2003; 55 (2): 63-79. DOI: 10.1007/s00251-003-0547-z.

113. Carlini F, Traore K, Cherouat $\mathbf{N}$ et al. HLA-G UTR haplotype conservation in the Malian population: association with soluble HLAG. PLoS One 2013; 8 (12): e82517. DOI: 10.1371/journal.pone.0082517.

114. Gros F, Sebti Y, de Guibert $S$ et al. Soluble HLA-G molecules increase during acute leukemia, especially in subtypes affecting monocytic and lymphoid lineages. Neoplasia 2006; 8 (3): 223-230. DOI: 10.1593/ neo.05703.

115. Jeong S, Park S, Park BW, Park Y, Kwon OJ, Kim HS. Human leukocyte antigen-G (HLA-G) polymorphism and expression in breast cancer patients. PLoS One 2014; 9 (5): e98284. DOI: 10.1371/journal. pone. 0098284 .

116. Adolf IC, Akan G, Mselle TF, Dharsee N, Namkinga LA, Atalar F. Implication of Soluble HLA-G and HLA-G +3142G/C Polymorphism in Breast Cancer Patients Receiving Adjuvant Therapy in Tanzania. Asian Pac J Cancer Prev 2019; 20 (11): 3465-3472. DOI: 10.31557/ APJCP.2019.20.11.3465.

117. Agnihotri V, Gupta A, Kumar L, Dey S. Serum sHLA-G: Significant diagnostic biomarker with respect to therapy and immunosuppressive mediators in Head and Neck Squamous Cell Carcinoma. Sci Rep 2020; 10 (1): 3806. DOI: 10.1038/s41598-020-60811-y.

Received February 21, 2021. Accepted March 19, 2021. 